\title{
Biological characteristics and classification of thermophilic actinomycetes showed extracellular hydrolytic enzymes producing ability isolated from compost
}

\author{
Thi Tuyen Do, Van Thang Le, Cao Cuong Ngo, Thi Thu Hong Do, and \\ Thi Hong Phuong Dang* \\ Vietnam - Russia Tropical Centre, 63 Nguyen Van Huyen, Cau Giay, Ha Noi, Vietnam
}

\begin{abstract}
Compost is a highly humified organic fertilizer, rich in nutrients and a source of a variety of aerobic microorganisms, including actinomycetes, which develop in response to different levels of temperature, humidity, oxygen and $\mathrm{pH}$. Microbes growing on the compost are believed to have the ability to produce extracellular hydrolytic enzymes. The purpose of this study was to determine the ability of thermophilic actinomycetes XM21 isolated from compost in producing hydrolytic enzymes, namely cellulase, amylase, protease, and lipase. The confirmation tests of hydrolytic enzymesproducing ability were conducted by inoculating the microbes into media containing cellulose, starch, gelatin and tween 80 , using the method of disc diffusion. The results showed that strain XM21 capable of extracellular enzymes producing, such as cellulase, protease, amylase, lipase. Strain XM21 can grow well with high cellulase activity in a wide range of temperature between $30-55 \mathrm{oC}$, optimum at $45 \mathrm{oC}$. The strain can grow well on different media, utilized carbon sources with $\mathrm{pH} 5-10$, and salinity of 0 $5 \%$. On the agar plate, the strain has white aerial mycelia, the mature spore chains appeared spirals, moderately long, bearing 10 to 35 spores each. Based on the biological characteristics and phylogenetic analysis of $16 \mathrm{~S}$ rDNA, it can be concluded that strain XM21 is close to Streptomyces flavovariabilis $(98,12 \%)$, hence identified as Streptomyces flavovariabilis XM21.
\end{abstract}

\section{Introduction}

Composting is a self-heating, aerobic, and biodegradation process that supplies humus and other nutrients to the soil (Rawat and Johri, 2013). Composting sites represent one of the anthropocentric environments in which it is possible to find extremophiles, which are organisms that are capable of living in particular ecosystems that are characterized by extreme parameters of temperature, $\mathrm{pH}$ values, salinity, etc... The composting involves the synergistic action of bacteria, actinobacteria, and fungi. Thermophilic actinomycetes is

\footnotetext{
* Corresponding author: tuyendodhkh@gmail.com
} 
known to possess unique metabolic rates and physical properties that prove to be beneficial in composting. They are known to improve the quality of compost and increase its nutrient content.The predominance of thermophilic actinomycetes is generally observed in thermobiotic condition generated by the preceding bacteria (in the later stages of composting) [9], [13].

Actinomycetes genera such as Streptomyces, Microbispora, Cellulosimicrobium, Micromonospora, Thermobispora, Thermomonospora, Thermobifida... were reported to be involved in the composting process [8], [6], [7]. He composition of actinobacterial communities varies during various stages of composting. They also reduce the odor of compost as they are able to completely digest the organic matter present in compost ((Xiao et al., 2011; Ohta and Ikeda, 1978). The thermophilic actinomycetes (Streptomyces sp. No. 101) have been shown to produce many extracellular enzymes and deodorize the compost (Tanaka et al., 1995). They also suppress the growth of pathogens by secreting antibiotics along with the breakdown of organic matter which provides an additional advantage of using compost in order to enhance soil nutrients and also suppressing the development of plant diseases [11]. Moreover, the addition of compost to contaminated soil enhances the bioremediation rates of pollutants such as polycyclic aromatic hydrocarbons, petroleum, and heavy metals (Chen et al., 2015). Some thermophilic actinomycetes are capable of suppressing plant diseases, such as good health of crop plants which leads to increase in crop yield (Iijima and Ryusuke, 1996), therefore, these thermotolerant actinomycetes could be used as alternative to commercial homestead [2], [14]. The aim of this study is to determine biological characteristics and classification of thermophilic actinomycetes showed extracellular hydrolytic enzymes producing ability isolated from compost.

\section{Materials and methods}

\subsection{Materials}

Sampling of the Compost: The Actinomycetes strains were isolated from 10 compost samples which mainly composed of cow dung, fresh grass and sawdust from different compost sites from farms of Thanh Hoa province in Viet Nam. A compost sample was aseptically collected on the 5 th -7 th day of composting when the temperature, as measured by PT100 thermo-sensors (Thermo Scientific, Waltham, MA, USA) placed in the core of the pile, was $50^{\circ} \mathrm{C}$.

Phytopathogens: The phytopathogens, namely, Fusarium oxysporum VTCCF-1301, Aspergillus niger VTCCF-001, Fusarium solani VTCCF-1302, were used. Inoculum of this spore suspension was prepared individually as suggested previously [15]. These fungal cultures were then stored on potato dextrose agar (PDA) slants.

\subsection{Methods}

\subsubsection{Isolation of the Thermophilic Strains}

For the isolation of the thermophilic strains, $1 \mathrm{~g}$ of compost was dilute with $100 \mathrm{ml}$ sterile distilled water and homogenized by constant shaking. Subsequently, $100 \mu \mathrm{L}$ of this solution was suitably diluted and plated in a liquid mineral medium containing cellulose (with Nalidixic acid $(50 \mu \mathrm{g} / \mathrm{mL})$, Nystatin $(25 \mu \mathrm{g} / \mathrm{mL})$ to inhibit the growth of fungi and bacteria) and incubated for 7 days at $50^{\circ} \mathrm{C}$. After 7 days of incubation, $100 \mu \mathrm{L}$ of this solution was plated on mineral agar medium containing cellulose and incubated for 7 to 14 days at $40^{\circ} \mathrm{C}$. Morphologically distinct actinomycete isolate was purified further using the same medium 
and maintained in $20 \%$ glycerol and stored at $-80 \circ \mathrm{C}$ for long-term use. After incubation, colonies were observed and confirmed by adding Gram's Iodine solution on the cellulose plate and left for 4-5 minutes. Finally staining of the plates were analyzed by noticing the formation of clear zones of cellulolytic activity around the growthAfter primary screening whose zone were appeared largest have selected for secondary screening in broth culture. According to potential cellulolytic activity in cell-free culture supernatant strains have selected for high enzyme activity [1], [5].

\subsubsection{Hydrolytic Enzyme Screening and Assay from Actinomycetes}

The Actinomycetes species were analyzed for their ability to produce various hydrolytic enzymes. The isolates were grown on substrate agar plates $(1 \%, \mathrm{w} / \mathrm{v}$, cellulose, gelatin, starch and tween 80 ) for the determination of cellulase, protease, amylase and lipase activity. The plates were incubated for 7 days on temperature of $40{ }^{\circ} \mathrm{C}$ and detected enzyme activity. The confirmation tests of hydrolytic enzymes-producing ability were conducted by using the method of disc diffusion [1], [2].

\subsubsection{Antimicrobial Compounds Extraction and Screening}

The actinomycetes isolates were cultivated into actinomycetes isolation broth and incubated for seven days at $40{ }^{\circ} \mathrm{C}$ and $150 \mathrm{rpm}$. After seven days, the culture was centrifuged at 10,000 rpm for $10 \mathrm{~min}$ and the supernatant used directly as the antimicrobial agents [4]. The extract was analyzed against plant pathogens (Fusarium oxysporum, Aspergillus niger, and Fusarium solani) using discdiffusion method ((Holder and Boyce, 1994). All experiments were performed in triplicate. Antifungal property was evaluated by measuring the inhibitory zone of culture supernatant on the plates surface and the results reported were the mean of three independent repeats [4], [3].

\subsubsection{The effect of incubation temperatures on growth strain $X M 21$}

The effect of incubation temperatures on growth was studied by inoculating $5 \mathrm{ml}$ of the spore suspension of the strain XM21 into $100 \mathrm{ml}$ liquid meniral medium containing cellulose in a temperature range from 30 to $65^{\circ} \mathrm{C}$ on a shaker at $150 \mathrm{rpm}$. Cells were collected after 7 days by centrifugation $(6000 \mathrm{xg}$ for $10 \mathrm{~min})$ and dried at $50^{\circ} \mathrm{C}$ for 2 days. Biomass yields of Actinomycetes were expressed as dried cell weights. Correlation between temperater and growth of actinomycetes by determining dry weight biomass $(\mathrm{mg} / \mathrm{ml})$ [7]. The remaining supernatant was collected and kept at $4^{\circ} \mathrm{C}$ for determinationof enzyme activity. The confirmation tests of hydrolytic enzymes-producing ability were conducted by using the method of disc diffusion [14], [3].

\subsubsection{Characterization of Potent Actinomycete Strain XM21}

The strain XM21 was selected for characterization studies based on its antagonistic potential and extracellular hydrolytic enzymes. Actinomycete isolates were tentatively classified by traditional identification methods, according to morphological characteristics, color of aerial mycelium and pigmentation produced on ISP media after 7 - 14 days (Shirling and Gottlieb, 1966; Goodfellow and Haynes, 1984) [12], [15]. Isolates were grown on ISP2 agar plates for morphological feature analysis of spores and spore-chains using a $\mathrm{BH} 2$ light microscope 
(Olympus Corporation, Tokyo, Japan) with a magnification of 100X or 400X. Assimilation of various sugars (Glucose, Lactose, rhamnose, Maltose, Saccharose, Galactose and Ribose), and melanin production was analyzed.

\subsection{6. $16 S$ rRNA gene sequencing and phylogenetic analysis}

Genomic DNA of the isolate XM 21 was extracted and sequenced using forward ( $27 \mathrm{f}$ - $\left(5^{\prime}\right.$ AGAGTTTGATCMTGCCTCAG-3')) and reverse (1492r - (5' TACGGYTACCTTGTTACGACTT-3')) primersperformed as previously described (Phi et al., 2010; Salam et al., 2017) [14], [10]. The PCR-Apparatus was programmed as follows: 5 min denaturation at $94{ }^{\circ} \mathrm{C}$, followedby 35 amplification cycles of 1 min at $94{ }^{\circ} \mathrm{C}$, $1 \mathrm{~min}$ of annealing at $55{ }^{\circ} \mathrm{C}$, and $2 \mathrm{~min}$ of extension at $72{ }^{\circ} \mathrm{C}$, followed by a $10 \mathrm{~min}$ final extension at $72{ }^{\circ} \mathrm{C}$. The purified PCR product of approximately $1400 \mathrm{bp}$ were purified and

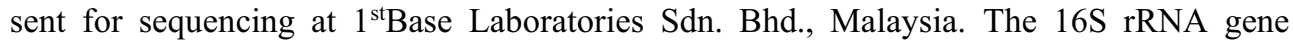
sequence was treated and blasted on GenBank database using Blast tool for the identification of the homology species (http://www.blast.ncbi.nlm/nihgov/Blast.cgi). A neighbor-joining phylogenetic tree based on 16S RNA gene sequences was computed using MEGA7 software (Tamura et al., 2013) [14].

\section{Results and discussions}

\subsection{Isolation of the Thermophilic Strains Producing Extracellular Hydrolytic Enzymes}

The selected substrates were added with the minimal mineral medium for the production of various enzymes because most of the enzymes are inducible. In total, 47 Actinomycetes were successfully recovered from the compost at $50^{\circ} \mathrm{C}$. Among the 47 Actinomycetes isolates, only 7 Actinomycetes $(14,9 \%)$ showed potent extracellular hydrolytic enzymes all tested (cellulase, protease, amylase and lipase). These enzymes is very important for the hydrolysis and recycling of nitrogen and carbon trapped in an insoluble form [41]. However, cellulase, protease, amylase and lipase activity was maximum in XM21 strain. Considering this fact, strain XM21 has the potential to degrade organic biomass from the environment. In a study, Gopinath et al. [42] analyzed the biodegrading ability of organic waste, tested by assaying various hydrolytic enzymes. These hydrolytic enzymes are useful in the composting process and help to breakdown complex molecules to simpler ones. Extracellular hydrolytic activity and the halo zone around the isolated strain $(\mathrm{mm})$ were presented in Table 1.

Table 1. Enzyme activity of Actinomycetes (halo zone in $\mathrm{mm}$ ) isolated from compost

\begin{tabular}{|c|c|c|c|c|}
\hline \multirow{2}{*}{ Actinomycetes } & \multicolumn{4}{|c|}{ Enzyme activity (mm) } \\
\cline { 2 - 5 } & Cellulase & Amylase & Protease & Lipase \\
\hline XM1 & 10 & 15 & 16 & 9 \\
\hline XM3 & 22 & 19 & 18 & 12 \\
\hline XM4 & 19 & 13 & 10 & 8 \\
\hline XM5 & 27 & 20 & 22 & 18 \\
\hline XM9 & 15 & 0 & 14 & 0 \\
\hline XM12 & 13 & 0 & 15 & 14 \\
\hline XM21 & 34 & 25 & 29 & 25 \\
\hline
\end{tabular}




\subsection{Actinomycetes and Their Antagonistic Properties Against the Selected Phytopathogens}

The antagonistic property of the Actinomycetes was tested against three plant pathogens. Among the 47 Actinomycetes isolates, only ten Actinomycetes $(21,3 \%)$ showed activity against at least one phytopathogen. A total of 7 Actinomycetes showed enzyme activity, five Actinomycetes strains have potent activity against $F$. oxysporum, A. niger, A. flavus. In the present investigation, XM21 showed potent activity against all tested plant pathogens. Antifungal activity and the corresponding zone of inhibition ( $\mathrm{mm}$ ) were presented in Table 2.

Table 2. Antagonistic activity of Actinomycetes (Zone of inhibition in $\mathrm{mm}$ ) isolated from compost against phytopathogens

\begin{tabular}{|c|c|c|c|}
\hline \multirow{2}{*}{ Actinomycetes } & \multicolumn{3}{|c|}{ Zone of inhibition (mm) } \\
\cline { 2 - 4 } & F. oxysporum & A. niger & A.flavus \\
\hline XM1 & 0 & 9 & 0 \\
\hline XM3 & 15 & 0 & 18 \\
\hline XM4 & 14 & 0 & 11 \\
\hline XM5 & 17 & 10 & 12 \\
\hline XM9 & 0 & 0 & 8 \\
\hline XM12 & 0 & 15 & 19 \\
\hline XM21 & 18 & 15 & 19 \\
\hline
\end{tabular}

In a study, Verma et al. 2009, [30] isolated endophytic Actinomycetes from A. indica, A. Juss, and the isolated Streptomyces sp. showed antimicrobial activity. Recent studies indicated that the Streptomyces strains revealed protective bioactivity against various microbial pathogens also [31,32].

\subsection{The effect of incubation temperatures on growth strain XM21}

The culture conditions were optimizedand the optimum temperature for the culture was found to be $45{ }^{\circ} \mathrm{C}$ (the maximum dried cell weight of $4,4 \mathrm{mg} / \mathrm{ml}$ on the 7 th day of growth). The partially purified enzyme was found to have its optimum activity at $50{ }^{\circ} \mathrm{C}$ (hydrolysis zone $31,67 \mathrm{~mm}$ ), five degrees higher than for the optimum temperature for the culture (Figure 1). The culture, consisting of the whole organism has other enzymes such as the respiratory enzymes, that may be sensitive at higher temperatures, and hence a temperature above $45^{\circ} \mathrm{C}$ would begin to degrade it.

Moreover, the sampling was done in the core of the pile composting when the temperature was $50{ }^{\circ} \mathrm{C}$ and hence the higher temperature tolerance evolution is expected . Of course, it must be noticed that the enzyme has its optimum activity at $50{ }^{\circ} \mathrm{C}$ and remaind activity at 55 $\mathrm{oC}$, and this is unusually higher as we would have expected the optimum temperature to have been around the optimum temperature for the culture, say about $45^{\circ} \mathrm{C}$. The organism must be a result of evolution and gain mutation, which enables to work at such a high temperature of $50{ }^{\circ} \mathrm{C}$. The result is that we identified a species that produces enzyme that is tolerant and optimal at higher temperatures, of about $50^{\circ} \mathrm{C}$. The main use of this particular enzyme is that, this high temperature tolerant enzyme can be of immense use in compost where speed of process may be necessary for increased efficient decomposition of waste. 


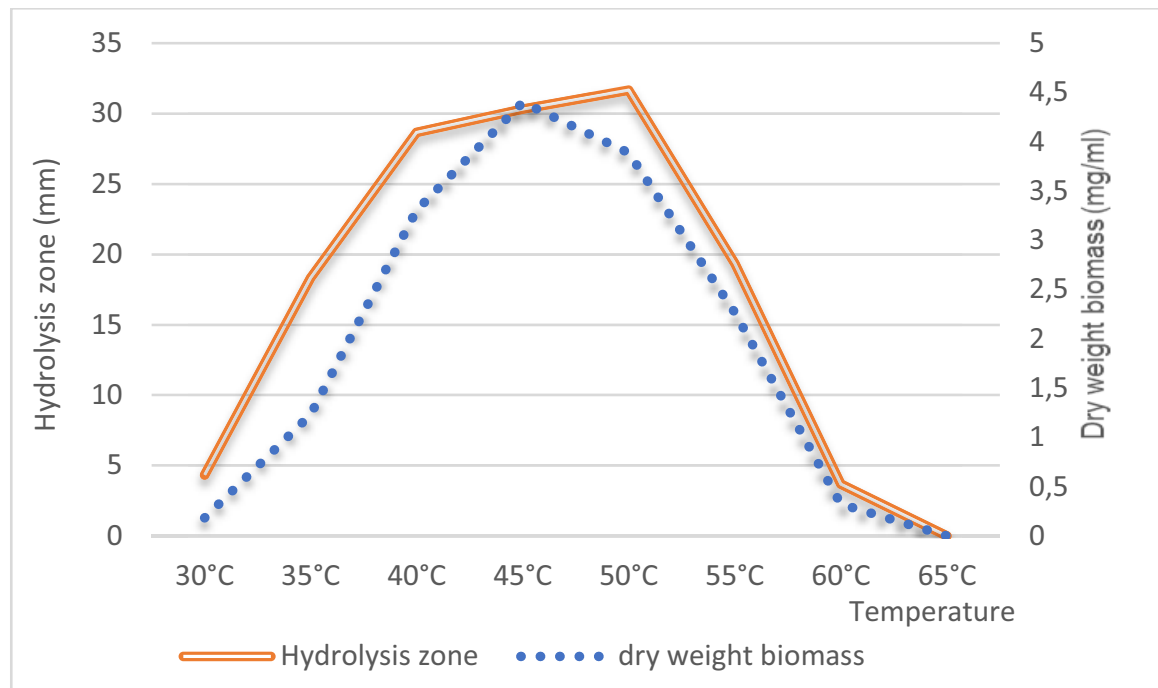

Fig. 1. Dried cell weight $(\mathrm{mg} / \mathrm{ml})$ and cellulase hydrolysis zone $(\mathrm{mm})$ of trains $\mathrm{XM} 21$ in a temperature range from 30 to $65^{\circ} \mathrm{C}$ on a shaker at $150 \mathrm{rpm}$ during 7 days growth.

\subsection{Characterization of Potent Actinomycete Strain XM21}

The colonial morphology of strain XM21 was consistent with its assignment to the genus Streptomyces (Williams et al., 1989). It formed an extensively branched substrate mycelium and aerial hyphae. The aerial spore mass was gray colored on several standard media. On the agar plate, the strain has white aerial mycelia, the mature spore chains appeared spirals, moderately long, bearing 10 to 35 spores (Figure 2).

The physiological and biochemical reactions of strain XM21 are shown in Table 3. Melanoid pigments not formed neither in peptone-yeast extract iron agar (ISP medium 6). As the sole carbon source, XM21 utilizes D-glucose, D-maltose, D-mannose, rhamnose, raffinose, L-arabinose for growth. The strain degrades gelatin, cellulose, starch, tween 80 and antimicrobial activities. The growth temperature of strain XM21 was $30-60{ }^{\circ} \mathrm{C}, \mathrm{pH} 5-10$, and salinity of $0-5 \%$ (Table 3 ).

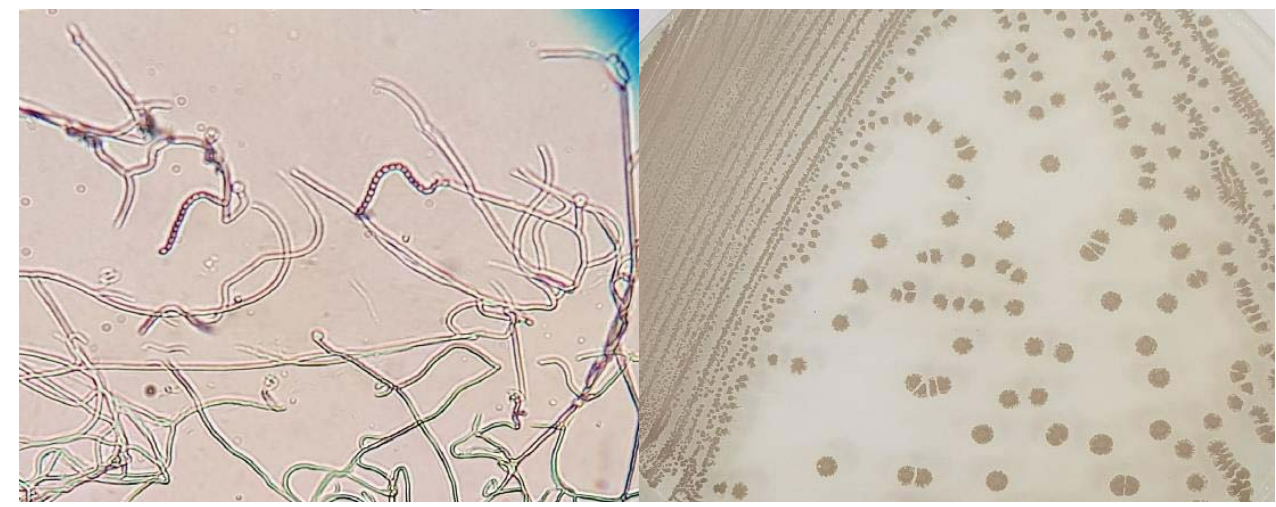

Fig. 2. Color of the aerial mycelium and the spore chain morphology of strain XM21 grown on ISP agar medium for 7 days at $40 \mathrm{oC}$ at magnification of $400 \mathrm{X}$ 
Table 3. Characterization of Potent Actinomycete Strain XM21

\begin{tabular}{cccc}
\hline Characterization & Strain XM21 & Characterization & Strain XM21 \\
\hline Gram's stain & + & $\begin{array}{c}\text { Cultural characteristics on different media } \\
\text { (Aerial mycelium/Substrate mycelium) }\end{array}$ \\
\hline Colony & $\Phi 2-3 \mathrm{~mm}$, Grey & ISP1 & Grey/ Faint grey \\
\hline $\begin{array}{c}\text { Melanin } \\
\text { production on ISP } \\
\text { medium 6 }\end{array}$ & Non & ISP3 & Grey/ Faint brown \\
\hline $\begin{array}{c}\text { Spore chain } \\
\text { morphology }\end{array}$ & RF & ISP4 & Grey/ Grey \\
\hline $\begin{array}{c}\text { Number of spores } \\
\text { /chain }\end{array}$ & 10 to 35 spores & ISP5 & Grey/ Faint yellow \\
\hline $\begin{array}{c}\text { Max NaCl } \\
\text { tolerance (w/v) }\end{array}$ & $5 \%$ & ISP7 & Faint grey/Brown \\
\hline Growth on sole carbon source (1+, w/v) & ISP8 & Grey/ Faint grey \\
\hline Glucose & + & ISP9 & Grey/ Grey \\
\hline Lactose & + & Cellulose & + \\
\hline Maltose & + & Gelatin & + \\
\hline Saccharose & + & Starch & + \\
\hline Galactose & + & Tween 80 & + \\
\hline Rhamnose & + & Antimicrobial & activities \\
\hline Ribose & - & & + \\
\hline & + Positive; - Negative & & + \\
\hline
\end{tabular}

\subsection{Identification results}

XM21 had the biggest clear zone among all the seventeen isolates in the enzyme screening test. The isolate was sent for sequencing using rRNA technology and for phylogenetic analysis. The nearly complete $16 \mathrm{~S}$ rRNA gene sequence (11169 nucleotides) for the strain XM21 was aligned with other 16S rRNA sequences of representative Streptomyces species retrieved from the GenBank databases by using BLAST searches (Altschul et al., 1997). Based on the biological characteristics and phylogenetic analysis of 16S rDNA, it can be concluded that strain XM21 is close to Streptomyces flavovariabilis FJ792572.1 (98,12\%) (shown in Figure 3), hence identified as Streptomyces flavovariabilis XM21.

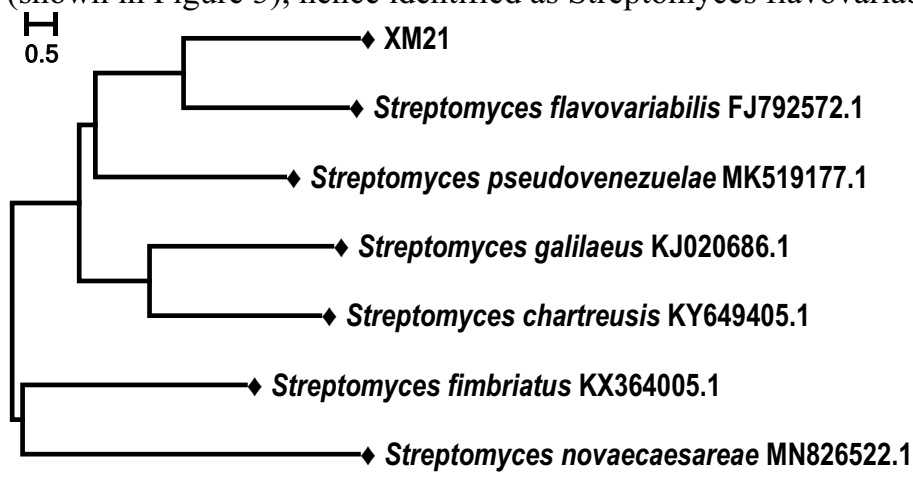

Fig. 3. Phylogenetic tree of strain XM21, based on the $16 \mathrm{~S}$ rRNA region sequences 


\section{Conclusions}

The suitable strain XM21 showed extracellular hydrolytic enzymes producing ability and Antifungal activity was characterized by morphological, biochemical. The results showed that strain XM21 capable of extracellular enzymes producing, such as cellulase, protease, amylase, lipase. Strain XM21 can grow well with high cellulase activity in a wide range of temperature between $30-55 \mathrm{oC}$, optimum at $45 \mathrm{oC}$. The strain can grow well on different media, utilized carbon sources with $\mathrm{pH} 5-10$, and salinity of $0-5 \%$. On the agar plate, the strain has white aerial mycelia, the mature spore chains appeared spirals, moderately long, bearing 10 to 35 spores each. Based on the biological characteristics and phylogenetic analysis of $16 \mathrm{~S}$ rDNA, it can be concluded that strain XM21 is close to Streptomyces flavovariabilis $(98,12 \%)$, hence identified as Streptomyces flavovariabilis XM21.

This work are studied in the biotechnology laboratory and financially supported by Vietnam - Russia Tropical Centre. The authors also thank the farm of Thanh Hoa province in Viet Nam for providing sampling of the Compost used in this study.

\section{References}

1. M.Z. Alam, M.A. Manchur, M.N. Anwar, Streptomyces omiyaensis. Biol Sci, 7, 16471653 (2004)

2. N.A. Al-Dhabi, G. A. Esmail, A. M. Ghilan and M. V. Arasu, Sustainability, 11, 6845 (2019)

3. I. Holderand, S. Boyce, Burns, 20, 426-429 (1994)

4. F. Mauch, B.M. Mani, T., Boller, Plant Physiol., 88, 936-942 (1988)

5. A. Niti K, S. Krishpa B, Int. J. for Research in Applied Science \& Engineering Technology (IJRASET), 7(3) (2019)

6. N. E. El-Naggar, N. A.M. Abdelwahed, W, I.A. Saber, Brazilian J. Microbiol., 45(2), 743-756 (2014)

7. E.L. Naggar, A.A. Sherief, S.S. Hamza, Afric J. Biotechnol., 10(56), 11998-12011 (2011)

8. S. Priyanka, Isolation, J. Biotech. Biores, 1(5), JBB.000523 (2019)

9. M. Papale, et al., Microorganisms, 9, 218 (2021)

10. A. Sacido and O. Genilloud, Microbial ecology, 49, 10-24 (2005)

11. S. Srisamai, P. Srikhampa and W. Pathom-aree, Chiang Mai J. Sci., 40(2), 294-298 (2013)

12. E. T. Shirling and D. Gottlieb, Int. J. of Systematic and Evolutionary Microbiol., 16, 313-340 (1966)

13. L. Shivlata and T. Satyanarayana, Front. Microbiol. 6, 1014 (2015)

14. T. H. N. Vu et al., The J. of General and Applied Microbiol. (2019)

15. S.A. Waksman, The actinomycetes, classification, identification and descriptions of genera and species. Vo. 2, 61-292 (The Williams and Wilkins Company, Baltimore, 1961) 